\title{
The Practical Significance of Moral Self-Discipline and Other Rules of Etiquette and Law in the Confucian Culture to the Governance of Cyberspace in Colleges and Universities
}

\author{
Ping Liu \\ Yunnan Open University \\ Kunming, China
}

\begin{abstract}
The governance of college cyberspace is related to the formation and correction of college students' world outlook, outlook on life and values, and the clearness of college cyberspace will directly affect the stability and development of colleges and universities. Based on the scientific understanding of self-discipline and heteronomy in Confucian culture, this paper hopes to put forward practical suggestions on the path of optimizing the governance of university cyberspace on the basis of carrying forward excellent traditional culture.
\end{abstract}

Keywords—self-discipline; heteronomy; cyberspace

\section{INTRODUCTION}

College network space is a free and open space for college students to express their opinions. Contemporary college students have strong patriotic feelings. With the awakening and enhancement of their awareness of rights, they care about major events at home and abroad, social and public affairs, and are very sensitive to matters involving their own interests. College life is an important stage for college students to form and develop their world outlook, outlook on life and values, but on the other hand, there are still some deficiencies in identifying and identifying bad information on the Internet, which is easy to cause the loss and deviation of college students' beliefs.

\section{OVERVIEW OF MORAL SELF-DISCIPLINE AND OTHER RULES OF ETIQUETTE AND LAW}

Five thousand years of Chinese civilization has a long history. The "three guidelines" in the book of rites university put forward: "the way of university is to be clear and virtuous, to be close to the people and to stop at perfection. "Eight items" in "Gewu", "Zhizhi", "sincerity", "Zhengxin", "self-cultivation", "Qijia", "governing the country" and "pingtianxia", Gewu means to understand the truth of things, Zhizhi means to seek the truth of things, sincerity means to be honest and not to deceive yourself, to be cautious and independent, Zhengxin means not to act rashly, not to have evil thoughts, and to cultivate one's self with upright mind. With self-cultivation as the core, from oneself to man, from near to far, from inside to outside, from moral work, to realize the value of life "the way of University", that is to say, "correct oneself and correct people". Only when "power is inseparable from its classics" and "all changes are inseparable from its religion" can change without disorder, and only when we grasp the law of things' change, can we be just right.

The moral self-discipline of the Confucianists mainly starts from the analysis of human nature. They think that the motive force of self-discipline comes from the cultivation of moral emotion, and this kind of moral idea pursues a kind of ultimate moral perfect pursuit, which has the one sidedness of breaking away from the social practice of the subject, but it can't be denied that the moral self-discipline of the Confucianists is the product of rational thinking and has strict internal logic natures such as "eight items", embodies the idea of "benevolence" and has a strong humanistic color. From the beginning of the pre-Qin period, the philosophy wise men put forward the methods of "learning to its way", "introspection", "self-discipline", "self-discipline and selfdiscipline" and "practice is close to benevolence", which further deepen the connotation of moral self-discipline. For example, the motto of Southeast University in China: stop at the best, the motto of Xiamen University: keep on striving, stop at the best, and the motto of Jiangnan University: study hard and practice hard and stop at the best.

Heteronomy is mainly formed by combining the "law" and "rite" in Confucianism. The "rite law" is the product of ancient feudal society. They are the moral restraint stipulated in writing and the moral convention formed in social life, namely the moral restraint not stipulated in writing. Both of them play the role of moral heteronomy in ancient feudal society. "The rule of law, etiquette and punishment". "Long $\mathrm{Li}$ to the rule of state-owned Chang" means that only when the etiquette and law are complete can the country be in order. The existence of law not only ensures the formation of moral standards, but also strengthens the restraint of morality, which plays a positive role in the formation of moral selfdiscipline. That is to say, people are constantly honing in the environment of heteronomy formed by moral restraint, 
expose the unfavorable factors and behaviors that are not conducive to the ideological and political education activities of young college students and colleges, actively encourage people to create and carry forward the socialist theme, and promote the sustainable development of the network cultural environment.

Moreover, we should establish and perfect the management system of cyberspace in Colleges and universities. To create a good network education environment, we need a sound system guarantee. Colleges and universities should start from various systems to ensure the orderly operation of various departments.

\section{A. The Internal Restraint and Educational Guidance of Self-discipline}

After nearly a thousand years of precipitation and development, the thought of self-discipline is the product of historical development and constantly enriched and improved with the needs of the development of the times, which has the value of the times.

With the rapid development of Internet technology, the rule of law, scientific and reasonable management of college cyberspace is inevitable, which is one of the positions for ideological and political education of college students. The freedom of speech in cyberspace often becomes a platform for people to vent their dissatisfaction, which is usually irrational. In addition, China is in the transition period, and the social contradictions are relatively sharp. The so-called "follow the crowd", college students are easily infected by irrational speech, and become sensitive and sharp, resulting in many negative emotions. Secondly, contemporary college students have a strong sense of rights, and most of them are only children. Their self-control ability is weak. Once they think that their rights have been violated, they will often have excessive speech and behavior, and the bad information such as pornography, violence, superstition and heresy in the cyberspace or packaged bad information will affect their self-discipline.

\section{B. External Restraint and Guidance of Heteronomy}

With the further development of economic globalization, the collision between socialism with Chinese characteristics and capitalism has become an inevitable trend. Under certain conditions, the role of heteronomy is particularly important. Moral restraint and condemnation plus legal sanctions are the necessity of social development. What we need to make clear is that the construction of Qinglang cyberspace can not only rely on the internal moral constraints, but also need the cooperation of various mandatory laws and regulations.

The rule of law in cyberspace is imperative. This requires government agencies and industry associations to constantly improve the management system of network culture, so as to promote the governance of network space in Colleges and universities to deal with complex issues in accordance with rules and regulations. Moreover, we need to further supplement the compulsory rules and regulations from the legal norms, and fill in the loopholes of moral constraints.

In addition, the news media and the mass media should also play an important role in moral education, expose and

\section{THE OPTIMIZATION OF GOVERNANCE OF UNIVERSITY CYBERSPACE WITH SELF-DISCIPLINE AND HETERONOMY}

To sum up, we analyzed the inspiration of the thought of self-discipline and heteronomy in traditional culture to the optimization of the network space governance in Colleges and universities. In terms of self-discipline, we started from the participants of the network space governance in Colleges and universities, that is, college students, college educators, network technicians and operators respectively put forward reasonable optimization approaches,.

\section{A. Strengthening the Humanistic Care of the Governance of University Cyberspace}

Although the advanced technology brings convenience, but in pursuit of advanced technology, it is easy to ignore the rationality of human values, and the network environment dominated by technology is often lacking in humanistic care. However, the lack of humanistic care is contrary to the purpose of the governance of University cyberspace. The lack of humanistic care can't reflect the psychology of the participants in the governance of University cyberspace, can't play an effective role in the change of their own psychology, can't carry forward the core values, nor can it be said to guide and educate them. No matter how technology develops, it is impossible to replace the role of humanistic care.

Therefore, the important task of network space governance in Colleges and universities is to let the development of network technology return to the concept of human value, let technology reflect human and serve human.

\section{B. Based on Self-discipline, Improving Self-cultivation of Cyberspace Governance Subjects}

The network ideological and political educators in Colleges and universities have the closest relationship with students, and their network moral quality.

The level of network moral quality of college students has an important impact. Therefore, it is necessary to improve the moral quality of network ideological and political education workers in Colleges and universities, and to establish and improve moral constraints. At the same time, the moral quality of educators can form the moral quality model of college students, and become an important carrier 
of moral heteronomy content of college students at the same time of self-discipline.

In the cyberspace, college students should take active measures to strengthen self-protection, introspection and self-cultivation, rational use of the network, and consciously resist the invasion of bad information. To overcome the obstacles on the road of self-development, i.e. "to see the good, to cultivate the nature must be self-existent; to see the bad, to reflect on the nature must also be self-examination. If you are good, you will be good. "Second, "the ancient gentleman, his responsibility is also heavy to the week, his treatment is light to the agreement." To reflect on oneself comprehensively and strictly, we should make selfexamination habitual and normalized to find out our shortcomings and correct our mistakes. It is the most important level in the cultivation of Confucian ideal personality to combine knowledge with practice and to be cautious. Specifically speaking, it is to start from little things and cultivate their own moral cultivation. Caution, that is, bear in mind the admonition of "be careful in speech and act", check what you do, be careful in your behavior, and practice it in daily life learning, so as to open up a path for the improvement of comprehensive quality.

It is convenient to restrict news media and operators to abide by professional ethics. In the era of Internet information, the spread of bad information is lack of control, which leads to the impact of violence, pornography, westernization and other information and ideas on college students' values to varying degrees. Therefore, it is necessary for the network technicians to strengthen the supervision and construct the firewall of the network space in Colleges and universities. News media and operators should also abide by professional ethics standards, strengthen moral selfdiscipline, and actively build a clear cyberspace.

\section{Strengthening External Supplement and Restriction with the Support of Heteronomy}

Colleges and universities should strengthen the education of Ideological and moral cultivation. At the same time, they should use the moral restraint formed by students' internalization to promote the transition from network behavior to moral self-discipline. First of all, colleges and universities should make clear the goal and content of network moral education, and constantly enrich and improve it. Colleges and universities can set up courses about network moral according to local conditions. Secondly, colleges and universities should actively explore the cultural characteristics of the school represented by the school spirit and school motto, construct the campus network culture through the campus network, form a strong campus culture, and make the cultural characteristics the basis of the formation of the network morality of colleges and universities. Finally, we should constantly inject new vitality into the construction of campus cultural environment, actively tap the new connotation and carrier of school morality, set a moral example, and promote the continuous improvement of the content of school ideological and moral education.
Cultivate college students' network legal concept. Under the background of running a university according to law, colleges and universities should constantly cultivate college students' awareness and concept of the rule of law, so that they can understand the difference between "can do" and "can't do", and guide students to the norms of legal prohibition. Combining with the thoughts and principles of national laws and regulations, based on national laws and policies, combined with the actual situation of the school, the management mechanism in line with the health of the school's network environment is formulated, and various legal norms and systems are internalized into the school's rules and disciplines; secondly, the school's rules and disciplines in Colleges and universities should meet the needs of the development of the times, reflect the core of "people-oriented" and strengthen humanistic care, so as to Arouse the emotional resonance of teachers and students, and promote the implementation of relevant management system norms; finally, we should improve the reward and punishment regulations of campus network space, and make clear the reward and punishment, and commend the teachers and students who have done well, which is not only conducive to mobilizing teachers and students to jointly promote the construction of university network space law, but also to set an example to encourage others' behavior; at the same time, we need to harm the campus The punishment of the individual in the network environment urges the college students to set up the concept of network legal system. In this way, we can educate college students from the side, which is conducive to enhance their ability of identification and processing, and promote their awareness and ability of consciously resisting bad information.

\section{CONCLUSION}

Therefore, it is a long way to go to strengthen the management of college network space, promote the healthy development of campus network culture, and maintain social stability. Scientific understanding and promotion of the ideological core of moral self-discipline and heteronomy can provide us with a kind of spiritual resources that can be used for reference. It is undoubtedly of great practical significance in optimizing the governance of University cyberspace.

\section{REFERENCES}

[1] Huang Yongyi. Theoretical research on Network Ideological and Political Education [D]. Chongqing: Southwest University, 2011.

[2] Du Yue. Research on the governance of contemporary college students' network moral problems [D]. Guizhou Normal University; 2016.

[3] Zhang Chengjun. An analysis of the countermeasures to solve the moral problems of the campus network [J]. Qiqihar University (Philosophy and Social Sciences Edition). Issue 4, 2011.

[4] Wang Haiyan. Strategies for universities to deal with internet moral problems of "post-90s" college students [J]. Academic Theory; 2012, issue 6.

[5] Chen Decai. Analysis on the content and value of Confucian benevolence $[\mathrm{J}]$. Journal of Chongqing Urban Management Vocational College. 2009, issue 3. 
[6] Tan Zhujun. Governance of network public opinion in Colleges and Universities under the background of the rule of law in cyberspace [J] Journal of Taiyuan City Vocational and technical college. Issue 3, 2017.

[7] Song Yuanlin. The cultivation of network culture and the all-round development of human beings [J]. Contemporary world and socialism. 2008,05 . 